\title{
Postnatal treadmill exercise attenuates prenatal stress- induced apoptosis through enhancing serotonin expression in aged-offspring rats
}

\author{
Tae-Woon Kim', Eun-Sang Ji', Tae-Wook Kim², Sang-Won Lee ${ }^{3}$, Choong-Yeol Lee ${ }^{4}$, Sam-Jun Lee,* \\ 'Department of Physiology, College of Medicine, Kyung Hee University, Seoul, Korea \\ ${ }^{2}$ Department of Community Sport and Recreation, College of Health Science, Jangan University, Hwasung, Korea \\ ${ }^{3}$ Department of Physical Education, Korea Military Academy, Seoul, Korea \\ ${ }^{4}$ Department of Oriental Physiology, Gachon University College of Oriental Medicine, Seongnam, Korea \\ ${ }^{5}$ Department of Physical Education, College of Health, Welfare, and Education, Tong Myong University, Busan, Korea
}

\begin{abstract}
Maternal stress during pregnancy affects negative impact on health of offspring. In the present study, we compared the effects of maternal treadmill exercise and offspring treadmill exercise on prenatal stress-induced apoptosis and serotonin expression in offspring. Stress to the pregnant rats was induced by exposure of maternal rats to the hunting dog in an enclosed room. Exposure time was 10 min, three times per day, with a 1-h interval between exposures. This regimen was maintained from the seventh day of gestation until delivery. The pregnant rats in the exercise group were forced to run on a motorized treadmill for 30 min once a day, started 7 days after pregnancy until delivery. The offspring in the exercise group were forced to run on a motorized treadmill for 30 min once a day, started 4 weeks after birth for 4 weeks. In the present results, offspring exposed to prenatal stress exhibited lower Bcl-2 level and higher Bax level in the hippocampus, lower 5-hy-
\end{abstract}

droxytryptamine (5-HT) and tryptophan hydroxylase (TPH) expression in the dorsal raphe, and higher c-Fos expression in the locus coeruleus compared to age-matched control rats. Treadmill exercise of offspring suppressed Bax expression and enhanced $\mathrm{Bcl}-2$ expression in the hippocampus, increased 5-HT and TPH expression in the dorsal raphe, and enhanced c-Fos expression in the locus coeruleus of offspring. Treadmill exercise of offspring suppressed prenatal stress-induced apoptosis and normalized prenatal stress-induced alterations in serotonin synthesis and neuronal activation. However maternal treadmill exercise during pregnancy exerted no significant effect on offspring.

Keywords: Prenatal stress, Treadmill exercise, Apoptosis, Offspring, Rats

\section{INTRODUCTION}

Maternal stress during pregnancy or stress exposure early in postnatal life affects negative impact on health over the lifespan of offspring, including aberrations in brain development. These effects alter brain connectivity and function that may induce cognitive dysfunction and affective disorder in offspring (Lee and Goto, 2013; Wadhwa, 2005). Götz and Stefaniski (2007) suggested that prenatal stressor plays a critical role in determining the consequences on behavior and physiology of offspring in later life. Pre- natal stress is thought to have enduring effects and to influence stress response on late life (Wadhwa, 2005).

Alterations in serotonergic function trough alterations of 5-hydroxytryptamine (5-HT) and tryptophan hydroxylase (TPH) are associated with anxiety disorders (Sachs et al., 2013). Anxiety is associated with several brain areas, including the hippocampus, raphe nuclei, and locus coeruleus. Hippocampus is involved in the cognitive process and is an important brain region of emotion, including the modulation of anxiety states (Bannerman et al., 2004; Revest et al., 2009). 5-HT synthesis within the raphe nuclei, in-
${ }^{*}$ Corresponding author: Sam-Jun Lee

Department of Physical Education, College of Health, Social Welfare, and

Education, Tong Myong University, 428 Sinseon-ro, Nam-gu, Busan 608-711, Korea Tel: +82-51-629-2106, Fax: +82-51-629-2019, E-mail: anada23@tu.ac.kr

Received: December 12, 2014 / Accepted: February 22, 2015
This is an Open Access article distributed under the terms of the Creative Commons Attribution Non-Commercial License (http://creativecommons.org/licenses/by-nc/3.0/) which permits unrestricted non-commercial use, distribution, and reproduction in any medium, provided the original work is properly cited. 
cluding the dorsal and median raphe projections to the forebrain, plays a key role in mood disorders (López-Figueroa et al., 2004). $\mathrm{TPH}$, the rate-limiting enzyme of serotonin, directly determines the level of 5-HT synthesis (Boldrin et al., 2005). 5-HT and TPH are involved in cell survival, neurogenesis, and synaptic plasticity (Martinowich and $\mathrm{Lu}, 2008$ ), which are decreased by prenatal stress (Okado et al., 2001; Van den Hove et al., 2006) and aging (Hussain and Mitra, 2000; Tapia-Arancibia et al., 2008). Activation of locus coeruleus is associated with emotional status (Millan, 2003). Locus coeruleus is thought as a "stress circuit", because locus coeruleus activated after stressful stimuli (Ioti and Sugimoto, 2010).

Increased anxiety is linked to the overexpression of the pro-apoptotic protein Bax, which initiates neuronal cell death and causes selective impairment in hippocampal neurogenesis (Kim et al., 2010; Revest et al., 2009). Bcl-2 is known to inhibit apoptosis, and the overexpression of $\mathrm{Bcl}-2$ enhances neurogenesis and survival of newborn neuron (Kim et al., 2010; Zhang et al., 2006).

Exercise has been reported to have beneficial effects on brain function, such as managing anxiety and depression (De Moor et al., 2006; Seo et al., 2013). Exercise improves neuronal plasticity and psychological well-being (Hassmén et al., 2000; Matta Mello Portugal et al., 2013). In the present study, we examined the effects of treadmill exercise on apoptosis in offspring exposed to prenatal stress in relation with serotonin expression. Particularly, we compared the efficacy of maternal treadmill exercise during pregnancy and offspring treadmill exercise after birth.

\section{MATERIALS AND METHODS}

\section{Animals and treatments}

The experimental procedures were performed in accordance with the animal care guidelines of the National Institutes of Health $(\mathrm{NIH})$ and the Korean Academy of Medical Sciences. The animals were housed under controlled temperature $\left(23 \pm 2^{\circ} \mathrm{C}\right)$ and lighting (08:00 to 20:00 h) conditions with food and water available ad libitum. The pregnant Sprague-Dawley rats (12 weeks old) were obtained from commercial breeder (Orient Co., Seoul, Korea), and randomly divided into 3 groups ( $\mathrm{n}=5$ in each group): the control group, the stress-induced group, and the stress-induced and exercise group.

After delivery, the offspring were randomly divided into 4 groups ( $\mathrm{n}=7$ in each group): offspring in the maternal control group, offspring in the maternal stress group, offspring in the maternal stress with exercise group, and offspring with exercise in the maternal stress group.

\section{Induction of stress during pregnancy}

Stress to the pregnant rats was induced by exposure of maternal rats to the hunting dog in an enclosed room, according to the previous study (Seo et al., 2013). Exposure time was $10 \mathrm{~min}$, three times per day, with a 1-h interval between exposures. This regimen was maintained from the seventh day of gestation until delivery. The responses of pregnant rats to the hunting dog were watching from a distance, approaching and sniffing, and chasing with occasional mild attack. The hunting dog was able to approach, but could not injure the pregnant rats. The same hunting dog was used in all experiments.

\section{Exercise protocol}

The pregnant rats in the exercise group were forced to run on a motorized treadmill for 30 min once a day, started 7 days after pregnancy until delivery. The offspring with exercise group were forced to run on a motorized treadmill for 30 min once a day, started 4 weeks after birth for 4 weeks. The exercise load consisted of running at a speed of 2 meters/min for the first 5 min, 5 meters/ $\mathrm{min}$ for the next $5 \mathrm{~min}$, and 8 meters $/ \mathrm{min}$ for the last $20 \mathrm{~min}$, with a $0^{\circ}$ inclination.

\section{Tissue preparation}

The offspring were sacrificed 80 weeks after birth. The rats were anesthetized using Zoletil $50^{\circledR}(10 \mathrm{mg} / \mathrm{kg}$, i.p.; Vibac Laboratories, Carros, France), transcardially perfused with $50 \mathrm{mM}$ phosphate-buffered saline (PBS), and fixed with a freshly prepared solution consisting of $4 \%$ paraformaldehyde in $100 \mathrm{mM}$ phosphate buffer ( $\mathrm{PB}, \mathrm{pH}$ 7.4). The brains were dissected and post-fixed in the same fixative method overnight, and transferred to a $30 \%$ sucrose solution for cryoprotection. Forty $\mu \mathrm{m}$ thick coronal sections were made using a freezing microtome (Leica, Nussloch, Germany). On average 10 slice sections were collected from each rat, and the sections were used for immunohistochemistry.

\section{Western blot for Bax and Bcl-2}

Western blot was performed according to previously described methods (Kim et al., 2014). The hippocampus were collected, then immediately frozen at $-70^{\circ} \mathrm{C}$. Protein from each hippocampus was extracted. The tissues were homogenized with lysis buffer containing $50 \mathrm{mM}$ Tris- $\mathrm{HCl}(\mathrm{pH} 8.0), 150 \mathrm{mM} \mathrm{NaCl}, 10 \%$ glycerol, $1 \%$ Triton X-100, 1.5 mM MgCl $26 \mathrm{H}_{2} \mathrm{O}, 1$ mM EGTA, 1 mM PMSF, $1 \mathrm{mM} \mathrm{Na}_{2} \mathrm{VO}_{4}$, and $100 \mathrm{mM} \mathrm{NaF}$, then ultra- centrifuged at 50,000 rpm for $1 \mathrm{~h}$. Protein content was measured using a Bio-Rad colorimetric protein assay kit (Bio-Rad, Hercules, CA, USA). Pro- 
tein $(30 \mu \mathrm{g})$ was separated on SDS-polyacrylamide gels and transferred onto a nitrocellulose membrane. Anti-Bax (1:1,000; Santa Cruz Biotechnology, Dallas, TX, USA), anti-Bcl-2 (1:1,000; Santa Cruz Biotechnology), and anti- $\beta$-actin (1:1,000; Santa Cruz Biotechnology) were used as the primary antibodies. Horseradish peroxidase-conjugated anti-mouse antibodies for $\beta$-actin, Bax, and Bcl2 were used as the secondary antibodies. Experiments were performed in normal laboratory conditions and at room temperature, except for the transferred membranes. Transferred membranes were performed at $4^{\circ} \mathrm{C}$ with the cold pack and pre-chilled buffer. Band detection was performed using the enhanced chemiluminescence (ECL) detection kit (Santa Cruz Biotechnology).

\section{Immunohistochemistry for 5-HT and TPH}

To visualize 5-HT and TPH expression, immunohistochemistry for 5-HT and TPH in the dorsal raphe were performed, according to the previous study (Seo et al., 2013). The dorsal raphe spanning from Bregma 7.20 to $8.00 \mathrm{~mm}$ were obtained from each brain. The sections were incubated in PBS for $10 \mathrm{~min}$, and then washed three times in the same buffer. The sections were then incubated in $1 \% \mathrm{H}_{2} \mathrm{O}_{2}$ for $30 \mathrm{~min}$. The sections were selected from each brain and incubated overnight with rabbit anti-5-HT antibody (1:500, Abcam, Cambridge, UK) or rabbit anti-TPH antibody $(1: 1,000$; Oncogene Research Product, Cambridge, UK), and then with biotinylated rabbit secondary antibodies (1:200; Vector Laboratories, Burlingame, CA, USA) for another $1 \mathrm{~h}$. The secondary antibodies were amplified with the Vector Elite $A B C$ kit $^{\circledast}$ (1:100; Vector Laboratories). Antibody-biotin-avidin-peroxidase complexes were visualized using $0.03 \%$ 3,3'-diaminobenzidine (DAB), and the sections were mounted onto gelatin-coated slides. The slides were airdried overnight at room temperature, and the coverslips were mounted using Permount ${ }^{\circledast}$ (Fisher Scientific, Waltham, MA, USA).

\section{Immunohistochemistry for c-Fos}

Immunohistochemistry for c-Fos positive cells in the locus coeruleus (Bregma 9.84 to $9.96 \mathrm{~mm}$ ) was conducted, as the previously described method (Seo et al., 2013). The sections were incubated in PBS for 10 min and then washed three times in the same buffer. The sections were then incubated in $1 \% \mathrm{H}_{2} \mathrm{O}_{2}$ for $30 \mathrm{~min}$. Next, the sections were incubated overnight with rabbit anti-c-Fos antibody (1:500; Santa Cruz Biotechnology, Inc., Santa Cruz, CA, USA). The sections were then incubated for $1 \mathrm{~h}$ with anti-rabbit secondary antibody (1:200; Vector Laboratories). Next, the sections were incubated with avidin-biotin-peroxidase complex (1:100; Vector Laboratories) for $1 \mathrm{~h}$ at room temperature. The sections were incu- bated in a solution of $0.02 \% \mathrm{DAB}$ and $0.03 \% \mathrm{H}_{2} \mathrm{O}_{2}$ in $50 \mathrm{mM}$ Tris- $\mathrm{HCl}$ ( $\mathrm{pH}$ 7.6) for 5 min, washed with PBS and mounted onto gelatin-coated slides. The slides were air-dried overnight at room temperature, and the coverslips were mounted using Permount ${ }^{\circledast}$ (Fisher Scientific).

\section{Data analysis}

For confirming the expression of $\mathrm{Bax}$ and $\mathrm{Bcl}-2$, the detected bands were quantified using an Image-Pro Plus computer-assisted image analysis system (Media Cyberbetics Inc., Silver Spring, MD, USA). The numbers of 5-HT-positive and TPH-positive cells in the dorsal raphe and the number of c-Fos-positive cells in the locous coeruleus were counted hemilaterally under a light microscope (Olympus, Tokyo, Japan). The data were analyzed with oneway ANOVA and then Duncan post-hoc tests. All values are expressed as the mean \pm standard error of the mean (SEM), and $P<$ 0.05 was considered significant.

\section{RESULTS}

\section{Effect of treadmill exercise on Bax and $\mathrm{Bcl}-2$ expression in the hippocampus}

The effect of treadmill exercise on Bax and $\mathrm{Bcl}-2$ expression in the hippocampus is presented in Fig. 1. The level of Bax expression in the offspring in the maternal control group was set as 1.00. The level of Bax expression was $1.97 \pm 0.09$ in the offspring in the maternal stress group, $1.90 \pm 0.08$ in the offspring in the maternal stress with exercise group, and $1.52 \pm 0.07$ in the offspring with exercise in the maternal stress group. The expression of Bax in the offspring in the maternal stress group was higher than that in the offspring in the maternal control group. Postnatal treadmill exercise of offspring decreased the expression of Bax, in contrast, maternal exercise during pregnancy exerted no significant effect on Bax expression.

The level of Bcl-2 expression in the offspring in the maternal control group was set as 1.00. The level of $\mathrm{Bcl}-2$ expression was $0.58 \pm 0.05$ in the offspring in the maternal stress group, $0.67 \pm 0.05$ in the offspring in the maternal stress with exercise group, and 0.97 \pm 0.03 in offspring with exercise in the maternal stress group. The expression of $\mathrm{Bcl}-2$ in the offspring in the maternal stress group was lower than that in the offspring in the maternal control group. Postnatal treadmill exercise of offspring increased the expression of $\mathrm{Bcl}-2$, in contrast, maternal exercise during pregnancy exerted no significant effect on Bcl-2 expression. 


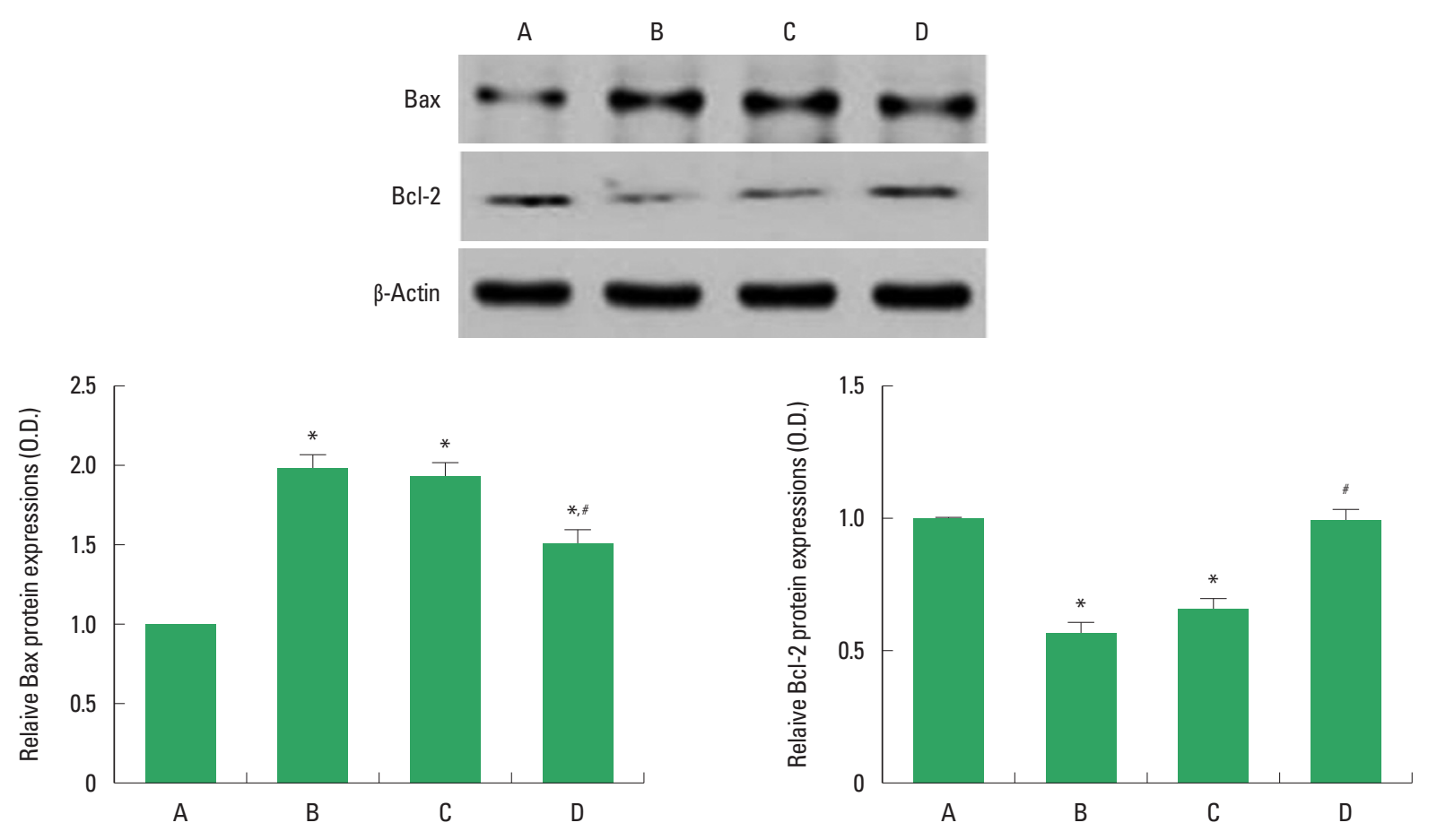

Fig. 1. Effect of treadmill exercise on Bax and Bcl-2 expression in the hippocampus. (A) Offspring in the maternal control group, (B) offspring in the maternal stress group, (C) offspring in the maternal stress with exercise group, and (D) offspring with exercise in the maternal stress group. The data are presented as the mean \pm standard error of the mean (SEM). * ${ }^{*}$ represents $P<0.05$ compared to the offspring in the maternal control group. ${ }^{*}$ represents $P<0.05$ compared to the offspring in the maternal stress group.

\section{Effect of treadmill exercise on 5-HT expression in the dorsal raphe}

The effect of treadmill exercise on 5-HT expression in the dorsal raphe is presented in Fig. 2. The number of 5-HT-positive cells was $225.50 \pm 9.96$ in the offspring in the maternal control group, $103.25 \pm 3.40$ in the offspring in the maternal stress group, $98.37 \pm 2.96$ in the offspring in the maternal stress with exercise group, and $168.75 \pm 4.51$ in offspring with exercise in the maternal stress group. The number of 5-HT-positive cells in the offspring in the maternal stress group was lower than that in the offspring in the maternal control group. Postnatal treadmill exercise of offspring increased the number of 5-HT-positive cells, in contrast, maternal exercise during pregnancy exerted no significant effect on the number of 5-HT-positive cells.

\section{Effect of treadmill exercise on TPH expression in the dorsal raphe}

The effect of treadmill exercise on TPH expression in the dorsal raphe is presented in Fig. 3. The number of TPH-positive cells was $342.50 \pm 11.32$ in the offspring in the maternal control group, $161.00 \pm 7.31$ in the offspring in the maternal stress group,
$158.33 \pm 8.23$ in offspring in the maternal stress with exercise group, and $236.83 \pm 11.58$ in the offspring with exercise in the maternal stress group. The number of TPH-positive cells in the offspring in the maternal stress group was lower than that in the offspring in the maternal control group. Postnatal treadmill exercise of offspring increased the number of TPH-positive cells, in contrast, maternal exercise during pregnancy exerted no significant effect on the number of TPH-positive cells.

\section{Effect of treadmill exercise on c-Fos expression in the locus coeruleus}

The effect of treadmill exercise on c-Fos expression in the locus coeruleus is presented in Fig. 4. The number of c-Fos-positive cells was $37.55 \pm 1.89$ in the offspring in the maternal control group, $60.89 \pm 4.60$ in the offspring in the maternal stress group, $68.33 \pm 4.17$ in the offspring in the maternal stress with exercise group, and $42.00 \pm 3.40$ in the offspring with exercise in the maternal stress group. The number of c-Fos-positive cells in offspring in the maternal stress group was higher than that in the offspring in the maternal control group. Postnatal treadmill exercise of offspring decreased the number c-Fos-positive cells, in contrast, ma- 

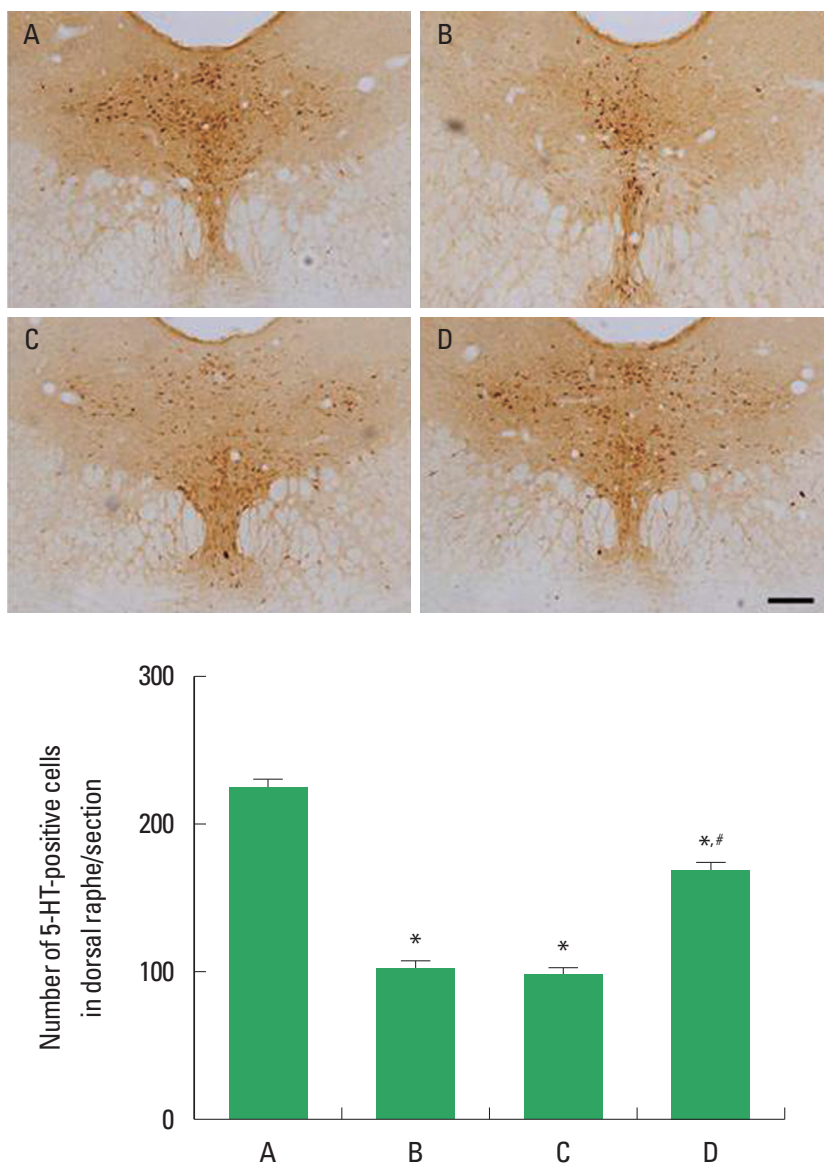

Fig. 2. Effect of treadmill exercise on 5-hydroxytryptamine (5-HT) expression in the dorsal raphe. Upper: Photomicrographs of 5-HT-positive cells. The scale bar represents $200 \mu \mathrm{m}$. Lower: number of 5 -HT-positive cells in each group. (A) Offspring in the maternal control group, (B) offspring in the maternal stress group, (C) offspring in the maternal stress with exercise group, and (D) offspring with exercise in the maternal stress group. The data are presented as the mean \pm standard error of the mean (SEM). ${ }^{*}$ represents $P<0.05$ compared to the offspring in the maternal control group. " represents $P<0.05$ compared to the offspring in the maternal stress group.

ternal exercise during pregnancy exerted no significant effect on the number of c-Fos-positive cells.

\section{DISCUSSION}

Bax is a promoter of apoptosis while $\mathrm{Bcl}-2$ is an anti-apoptotic regulator (Han et al., 2014). In the cerebral ischemia, Bax expression was higher and Bcl-2 expression was lower in the hippocampus of the control gerbils (Kim et al., 2014). Bax expression was increased and $\mathrm{Bcl}-2$ expression was decreased in the hippocampus of schizophrenic mice, which represents enhancement of apoptosis (Chung et al., 2014). Higher Bax level and lower Bcl-2 level were
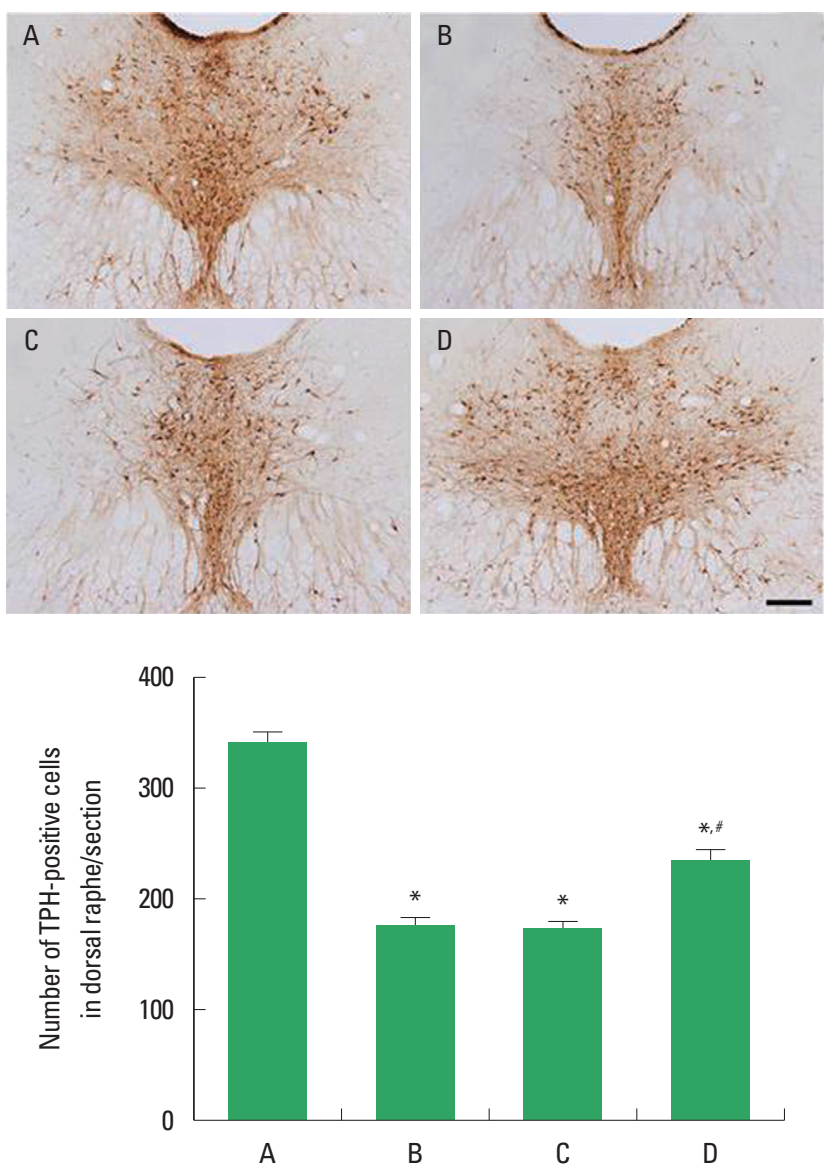

Fig. 3. Effect of treadmill exercise on tryptophan hydroxylase (TPH) expression in the dorsal raphe. Upper: Photomicrograph of TPH-positive cells. The scale bar represents $200 \mu \mathrm{m}$. Lower: number of TPH-positive cells in each group. (A) Offspring in the maternal control group, (B) offspring in the maternal stress group, (C) offspring in the maternal stress with exercise group, and (D) offspring with exercise in the maternal stress group. The data are presented as the mean \pm standard error of the mean (SEM). * ${ }^{*}$ represents $P<0.05$ compared to the offspring in the maternal control group. " ${ }^{*}$ represents $P<0.05$ compared to the offspring in the maternal stress group.

also reported in the attention deficit/hyperactivity disorder (ADHD) rats with Purkinje cell loss (Yun et al., 2014). In addition, enhanced Bax to Bcl-2 ratio was observed in the gastric ulcer-induced apoptosis in gerbils (Jeon et al., 2014). In the present study, offspring exposed to prenatal stress exhibited lower level of the $\mathrm{Bcl}-2$ and higher level of $\mathrm{Bax}$ in the hippocampus compared to age-matched control rats. The present results indicate that prenatal stress induced neuronal apoptosis in the hippocampus of offspring in late life.

5-HT is involved in the mood regulation, and serotonergic dysfunction is closely associated with mood disorders such as anxiety, depression, panic, and obsessive compulsive disorder (Seo et al., 

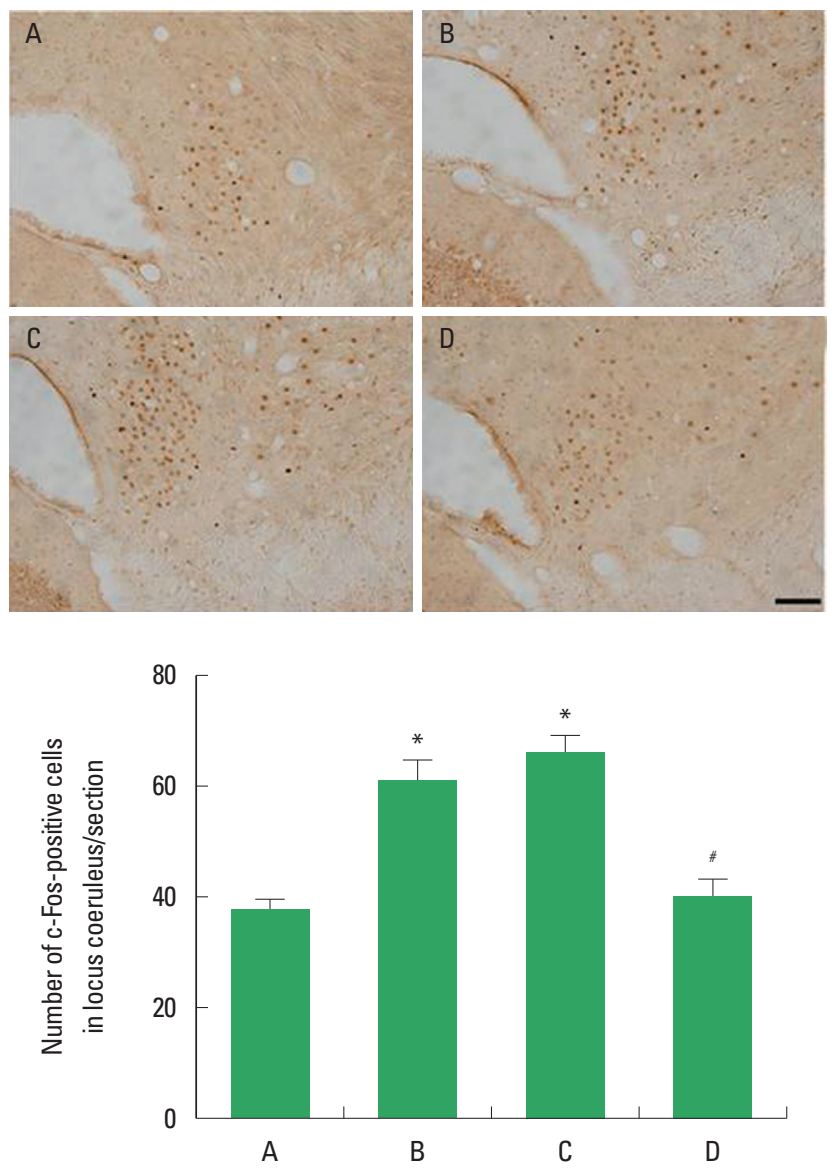

Fig. 4. Effect of treadmill exercise on c-Fos expression in the locus coeruleus. Upper: Photomicrographs c-Fos-positive cells. The scale bar represents 100 $\mu \mathrm{m}$. Lower: The number of c-Fos-positive cells in each group. (A) Offspring in the maternal control group, (B) offspring in the maternal stress group, (C) offspring in the maternal stress with exercise group, and (D) offspring with exercise in the maternal stress group. The data are presented as the mean \pm standard error of the mean (SEM). * ${ }^{*}$ represents $P<0.05$ compared to the offspring in the maternal control group. " represents $P<0.05$ compared to the offspring in the maternal stress group.

2013; Stamford et al., 2000; Sung et al., 2010). Stressful experiences, such as repeated separation of pups, suppressed 5-HT and TPH expression in the dorsal raphe and caused depression-like state in the maternal rats (Sung et al., 2010). Maternal separation induced anxiety-like behaviors, and this condition was associated with reduced 5-HT expression (Sachis et al., 2013). In the present study, offspring exposed to prenatal stress exhibited reduced expression of 5-HT and TPH in the dorsal raphe compared to agematched control rats. The present results indicate that prenatal stress induced depressive state of offspring in late life.

As stressful stimuli initiate neuronal activation, we also determined whether prenatal stress activated neurons in the locus coeru- leus. Viltart et al. (2006) reported that prenatal stress increased the number of Fos-immunoreactive neurons in the locus coeruleus. Increment of c-Fos expression indicates neuronal activation within several brain regions by stressful stimuli (Troakes and Ingram, 2009). Prenatal stress enhanced c-Fos expression in the hypothalamus and locus coeruleus of the maternal rats (Seo et al., 2013). In the present study, offspring exposed to prenatal stress showed increased c-Fos expression in the locus coeruleus compared to agematched control rats. The present results indicate that prenatal stress initiated neuronal activation in the locus coeruleus of offspring in late life.

Physical activity has an impact on mental health by modulating neurotransmitter release and expression of trophic factors, which can improve mood status (Matta Mello Portugal et al., 2013; Seo et al., 2013). Here in this study, we compared the effects of maternal treadmill exercise and offspring treadmill exercise on prenatal stress-induced apoptosis and serotonin expression.

Treadmill exercise suppressed Bax expression and enhanced Bcl2 expression in the hippocampus of schizophrenic mice (Chung et al., 2014). Treadmill exercise inhibited Bax level and increased Bcl-2 level with alleviation of Purkinje cell loss in the ADHD rats (Yun et al., 2014). In the present study, treadmill exercise of offspring exposed to prenatal stress suppressed Bax expression and enhanced $\mathrm{Bcl}-2$ expression in the hippocampus of offspring. These results suggest that treadmill exercise of offspring suppressed prenatal stress-induced apoptosis. However, maternal treadmill exercise showed no significant effect on Bax and Bcl-2 expression.

The positive effects of exercise are, in part, related to the effects of exercise on serotonergic function (Young, 2007). Wheel running increased 5-HT1A mRNA expression in dorsal raphe (Greenwood et al., 2005). Baek et al. (2012) reported that postnatal treadmill exercise increased 5-HT synthesis and TPH level in the dorsal raphe of rat pups subjected to maternal separation. In the present study, treadmill exercise of offspring exposed to prenatal stress increased 5-HT and TPH expression in the dorsal raphe of offspring. These results suggest that treadmill exercise of offspring alleviated stress-induced suppression on serotonin synthesis. However, maternal treadmill exercise showed no significant effect on 5-HT and TPH expression.

Treadmill exercise suppressed prenatal stress-induced c-Fos expression in the hypothalamus and locus coeruleus, as a result, ameliorated anxiety-like responses in the maternal rats (Seo et al., 2013). In the present study, treadmill exercise of offspring exposed to prenatal stress enhanced c-Fos expression in the locus coeruleus of offspring. These results suggest that treadmill exercise of off- 
spring suppressed prenatal stress-induced neuronal activation in the locus coeruleus of offspring in late lifer. However, maternal treadmill exercise showed no significant effect on c-Fos expression.

In conclusion, we confirmed that offspring exposed to stress during pregnancy exhibited enhanced apoptosis with alterations in serotonin synthesis and neuronal activation. Postnatal treadmill exercise of offspring suppressed prenatal stress-induced apoptosis and normalized prenatal stress-induced alterations in serotonin synthesis and neuronal activation. However maternal treadmill exercise during pregnancy exerted no significant effect on offspring. The present results suggest that postnatal treadmill exercise of offspring is effective to alleviate stress-induced neuronal changes during pregnancy.

\section{CONFLICT OF INTEREST}

No potential conflict of interest relevant to this article was reported.

\section{ACKNOWLEDGMENTS}

This work was supported by the National Research Foundation of Korea funded by the Korea Government [NRF-2010-327-G00123].

\section{REFERENCES}

Baek SS, Jun TW, Kim KJ, Shin MS, Kang SY, Kim CJ. Effects of postnatal treadmill exercise on apoptotic neuronal cell death and cell proliferation of maternal-separated rat pups. Brain Dev 2012;34:45-56.

Bannerman DM, Matthews P, Deacon RM, Rawlins JN. Medial septal lesions mimic effects of both selective dorsal and ventral hippocampal lesions. Behav Neurosci 2004;118:1033-1041.

Boldrini M, Underwood MD, Mann JJ, Arango V. More tryptophan hydroxylase in the brainstem dorsal raphe nucleus in depressed suicides. Brain Res 2005;1041:19-28.

Chung JW, Seo JH, Baek SB, Kim CJ, Kim TW. Treadmill exercise inhibits hippocampal apoptosis through enhancing $\mathrm{N}$-methyl-D-aspartate receptor expression in the MK-801-induced schizophrenic mice. J Exerc Rehabil 2014;10:218-224.

De Moor MH, Beem AL, Stubbe JH, Boomsma DI, De Geus EJ. Regular exercise, anxiety, depression and personality: a population-based study. Prev Med 2006;42:273-279.

Götz AA, Stefanski V. Psychosocial maternal stress during pregnancy affects serum corticosterone, blood immune parameters and anxiety behaviour in adult male rat offspring. Physiol Behav 2007;90:108-115.
Greenwood BN, Foley TE, Day HE, Burhans D, Brooks L, Campeau S, Fleshner M. Wheel running alters serotonin (5-HT) transporter, 5-HT1A, 5-HT1B, and alpha1b-adrenergic receptor mRNA in the rat raphe nuclei. Biol Psychiatry 2005;57:559-568.

Han JH, Kim DO, Yi JW, Park SW, Kang WJ, Choi YK, Kim SH, Ko IG, Jin JJ, Kim SE, Kim CJ. Dexmedetomidine, $\alpha 2$-adrenoceptor agonist, does not induce apoptosis in the brachial plexus of rats. Anim Cells Syst 2014;18:407-415.

Hassmén P, Koivula N, Uutela A. Physical exercise and psychological well-being: a population study in Finland. Prev Med 2000;30:17-25.

Hussain AM, Mitra AK. Effect of aging on tryptophan hydroxylase in rat brain: implications on serotonin level. Drug Metab Dispos 2000;28: 1038-1042.

Itoi K, Sugimoto N. The brainstem noradrenergic systems in stress, anxiety and depression. J Neuroendocrinol 2010;22:355-361.

Jeon JW, Lee JI, Shin HP, Cha JM, Joo KR, Kim SH, Ko IG, Jin JJ, Kim SE, Kim CJ. Adenosine A2A-receptor agonist polydeoxyribonucleotide promotes gastric ulcer healing in Mongolian gerbils. Anim Cells Syst 2014;18:399-406.

Kim M, Shin MS, Lee JM, Cho HS, Kim CJ, Kim YJ, Choi HR, Jeon JW. Inhibitory effects of isoquinoline alkaloid berberine on ischemia-induced apoptosis via activation of phosphoinositide 3-kinase/protein kinase B signaling pathway. Int Neurourol J 2014;18:115-125.

Kim SE, Ko IG, Kim BK, Shin MS, Cho S, Kim CJ, Kim SH, Baek SS, Lee EK, Jee YS. Treadmill exercise prevents aging-induced failure of memory through an increase in neurogenesis and suppression of apoptosis in rat hippocampus. Exp Gerontol 2010;45:357-365.

Lee YA, Goto Y. The effects of prenatal and postnatal environmental interaction: prenatal environmental adaptation hypothesis. J Physiol Paris 2013;107:483-492.

López-Figueroa AL, Norton CS, López-Figueroa MO, Armellini-Dodel D, Burke S, Akil H, López JF, Watson SJ. Serotonin 5-HT1A, 5-HT1B, and 5-HT2A receptor mRNA expression in subjects with major depression, bipolar disorder, and schizophrenia. Biol Psychiatry 2004;55:225233.

Martinowich K, Lu B. Interaction between BDNF and serotonin: role in mood disorders. Neuropsychopharmacology 2008;33:73-83.

Matta Mello Portugal E, Cevada T, Sobral Monteiro-Junior R, Teixeira Guimarães T, da Cruz Rubini E, Lattari E, Blois C, Camaz Deslandes A. Neuroscience of exercise: from neurobiology mechanisms to mental health. Neuropsychobiology 2013;68:1-14.

Millan MJ. The neurobiology and control of anxious states. Prog Neurbiol 2003;70:83-244.

Okado N, Narita M, Narita N. A biogenic amine-synapse mechanism for mental retardation and developmental disabilities. Brain Dev 2001;1: 
S11-S15.

Revest JM, Dupret D, Koehl M, Funk-Reiter C, Grosjean N, Piazza PV, Abrous DN. Adult hippocampal neurogenesis is involved in anxiety-related behaviors. Mol Psychiatry 2009;14:959-967.

Sachs BD, Rodriguiz RM, Siesser WB, Kenan A, Royer EL, Jacobsen JP, Wetsel WC, Caron MG. The effects of brain serotonin deficiency on behavioural disinhibition and anxiety-like behaviour following mild early life stress. Int J Neuropsychopharmacol 2013;14:1-14.

Seo JH, Kim TW, Kim CJ, Sung YH, Lee SJ. Treadmill exercise during pregnancy ameliorates post-traumatic stress disorder-induced anxiety-like responses in maternal rats. Mol Med Rep 2013;7:389-395.

Stamford JA, Davidson C, McLaughlin DP, Hopwood SE. Control of dorsal raphé 5-HT function by multiple 5-HT(1) autoreceptors: parallel purposes or pointless plurality? Trends Neurosci 2000;23:459-465.

Sung YH, Shin MS, Cho S, Baik HH, Jin BK, Chang HK, Lee EK, Kim CJ. Depression-like state in maternal rats induced by repeated separation of pups is accompanied by a decrease of cell proliferation and an increase of apoptosis in the hippocampus. Neurosci Lett 2010;5;470:86-90.

Tapia-Arancibia L, Aliaga E, Silhol M, Arancibia S. New insights into brain BDNF function in normal aging and Alzheimer disease. Brain Res Rev 2008;59:201-220.

Troakes C, Ingram CD. Anxiety behaviour of the male rat on the elevated plus maze: associated regional increase in c-fos mRNA expression and modulation by early maternal separation. Stress 2009;12:362-369. Van den Hove DL, Steinbusch HW, Scheepens A, Van de Berg WD, Kooiman LA, Boosten BJ, Prickaerts J, Blanco CE. Prenatal stress and neonatal rat brain development. Neuroscience 2006;137:145-155.

Viltart O, Mairesse J, Darnaudéry M, Louvart H, Vanbesien-Mailliot C, Catalani A, Maccari S. Prenatal stress alters Fos protein expression in hippocampus and locus coeruleus stress-related brain structures. Psychoneuroendocrinology 2006;31:769-780.

Wadhwa PD. Psychoneuroendocrine processes in human pregnancy influence fetal development and health. Psychoneuroendocrinology. 2005;30:724-743.

Young SN. How to increase serotonin in the human brain without drugs. J Psychiatry Neurosci 2007;32:394-399.

Yun HS, Park MS, Ji ES, Kim TW, Ko IG, Kim HB, Kim H. Treadmill exercise ameliorates symptoms of attention deficit/hyperactivity disorder through reducing Purkinje cell loss and astrocytic reaction in spontaneous hypertensive rats. J Exerc Rehabil 2014;10:22-30.

Zhang R, Xue YY, Lu SD, Wang Y, Zhang LM, Huang YL, Signore AP, Chen J, Sun FY. Bcl-2 enhances neurogenesis and inhibits apoptosis of newborn neurons in adult rat brain following a transient middle cerebral artery occlusion. Neurobiol Dis 2006;24:345-356. 